\title{
MIDAS
}

Museus e estudos interdisciplinares

$7 \mid 2016$

Varia

\section{Colecionar arte: conversas a partir de coleções particulares}

Collecting art: Conversations about private collections

Adelaide Duarte

\section{OpenEdition}

Journals

\section{Edição electrónica}

URL: http://journals.openedition.org/midas/1060

DOI: $10.4000 /$ midas. 1060

ISSN: 2182-9543

\section{Editora:}

Alice Semedo, Paulo Simões Rodrigues, Pedro Casaleiro, Raquel Henriques da Silva, Ana Carvalho

Refêrencia eletrónica

Adelaide Duarte, «Colecionar arte: conversas a partir de coleções particulares », MIDAS [Online],

7 | 2016, posto online no dia 29 novembro 2016, consultado no dia 01 maio 2019. URL : http:// journals.openedition.org/midas/1060; DOI : 10.4000/midas.1060

Este documento foi criado de forma automática no dia 1 Maio 2019

\section{(c) (i) (2)(2)}

Midas is licensed under a Creative Commons Attribution-NonCommercial-ShareAlike 3.0 International License 


\title{
Colecionar arte: conversas a partir de coleções particulares
}

\author{
Collecting art: Conversations about private collections
}

\section{Adelaide Duarte}

1 Num tempo em que o associativismo denota dificuldade em atrair gente para a causa museológica devido às imensas solicitações que a sociedade impõe, implementar projetos através dos grupos dos amigos dos museus resulta de um meritório envolvimento dos seus (poucos) associados que deve ser considerado e potenciado. A Associação Amigos do Museu do Chiado, vocacionada para apoiar o Museu Nacional de Arte Contemporânea Museu do Chiado (MNAC-MC), foi instituída em 1995, ao tempo da reinauguração do Museu. Desde a sua criação que acompanha as sucessivas direções, divulgando e dinamizando as atividades do Museu e contribui para o enriquecimento da sua coleção. A Associação é responsável por uma programação própria que divulga entre os associados e o público em geral, sobretudo através do seu sítio online: http:// amigos.museuartecontemporanea.pt.

\section{Como surgiu a iniciativa?}

2 A direção da associação, numa linha de continuidade programática e de composição, iniciou um projeto de conversas a partir de coleções particulares de arte moderna e contemporânea (finais de 2013), conduzidas por personalidades ligadas ao mundo da arte e da academia. A autora, que tem vindo a trabalhar temas do colecionismo (Duarte 2012), agarrou com entusiasmo a ideia proposta pelo presidente da Associação. Francisco Capelo é um colecionador exigente e eclético, com vasta experiência neste domínio: reuniu a coleção de arte moderna e contemporânea de José Berardo, exposta nas galerias do Centro Cultural de Belém (Capelo 1996); a coleção de design e da moda que dá corpo ao MUDE - Museu do Design e da Moda, Coleção Francisco Capelo, também em exibição na baixa lisboeta; ou, ainda, a coleção de marionetas tradicionais portuguesas e máscaras africanas e do sudeste asiático, depositadas no Museu da Marioneta, em Lisboa. O ciclo conta, ainda, com o contributo da historiadora de arte Raquel Henriques da Silva, 
membro dos corpos sociais da Associação, que, desde o primeiro momento, tem cooperado na sua concretização, moderado e participado nas sessões.

\section{Porquê este projeto?}

3 Colecionar como un art du secret (Thomas 1997). Metáfora alusiva ao ambiente de discrição que tantas vezes envolve esta prática, as oportunidades para conhecer a formação de coleções privadas na primeira pessoa são raras. Justificam esta circunstância razões de privacidade inerentes ao espaço doméstico, motivos de cultura ou do foro financeiro. Por conseguinte, conhecer uma coleção privada pressupõe o prazer e a generosidade da partilha pelo seu colecionador. O modus operandi, o gosto implícito ou construído, as estratégias adotadas, os meandros do sistema da arte, o mercado e os seus valores, as vicissitudes que envolvem a reunião das obras são assuntos sobre os quais o testemunho do colecionador enriquece sobremaneira a narrativa da coleção.

4 Colecionar é uma atividade que se perde na memória da história coletiva; foi origem de museus públicos, desde os gabinetes de curiosidades aos grandes museus nacionais criados no século XIX, e contribui, continuadamente, para o enriquecimento dos seus fundos (Schlosser 2012; Pomian 2003). Em Portugal, um país de parcos recursos económicos, esta atividade manifesta uma escassa expressão pública. Os colecionadores particulares ativos, pouco numerosos, geralmente preferem manter a discrição sobre os seus tesouros. Este projeto pretende confrontar esta tendência, valorizando o lugar dos colecionadores junto de públicos interessados.

Definem-se dois objetivos principais: por um lado, mapear e identificar os tipos de colecionador ativos na nossa sociedade (destacando, numa perspetiva sociológica, os aspetos culturais e económicos); por outro, analisar as tendências do colecionismo na sua relação com as características da coleção (determinar os traços distintivos das coleções: coleções de mercado, coleções ecléticas, coleções históricas, coleções de vanguarda). Sempre que houver consentimento, tentar-se-á inventariar as coleções para garantir o conhecimento da sua história, da cultura material, salvaguardando a sua dispersão em leilão.

6 Acresce que, entre os associados, há colecionadores amantes da arte, com apetência para desenvolver uma ação cívica voluntariosa e de mecenato em prol da instituição. É nosso propósito criar condições de aproximação ao Museu, incitando à generosidade, nomeadamente através dos benefícios do depósito ou da doação de obras.

\section{A que colecionadores temos dado a palavra?}

7 Temos vindo a ouvir diferentes tipos de colecionador, observando a formação das suas coleções na perspetiva das suas vivências e do grupo a que pertencem: galeristas que trabalham na venda e na promoção do objeto artístico; críticos de arte que contribuem sobretudo para atribuir valor simbólico; a compradores, por exemplo, do setor terciário (arquitetos, empresários, advogados e médicos), cujo perfil varia em função do tipo de coleção e do nível de envolvimento (Poli 2002).

O galerista Carlos Bessa Pereira abriu o ciclo (fig. 1). Colecionador proveniente do negócio farmacêutico, Bessa Pereira começou por reunir obras de artes decorativas do século XVIII, vindo posteriormente a interessar-se pela arte contemporânea portuguesa. 
Recentemente (2013), iniciou um projeto galerístico dedicado ao design do pós-guerra, com incidência no design português. O percurso das coleções, os autores eletivos, o mercado do design e a especificidade portuguesa (José Espinho, António Garcia, Daciano da Costa e Eduardo Afonso Dias) foram assuntos desenvolvidos numa conversa conduzida por Francisco Capelo.

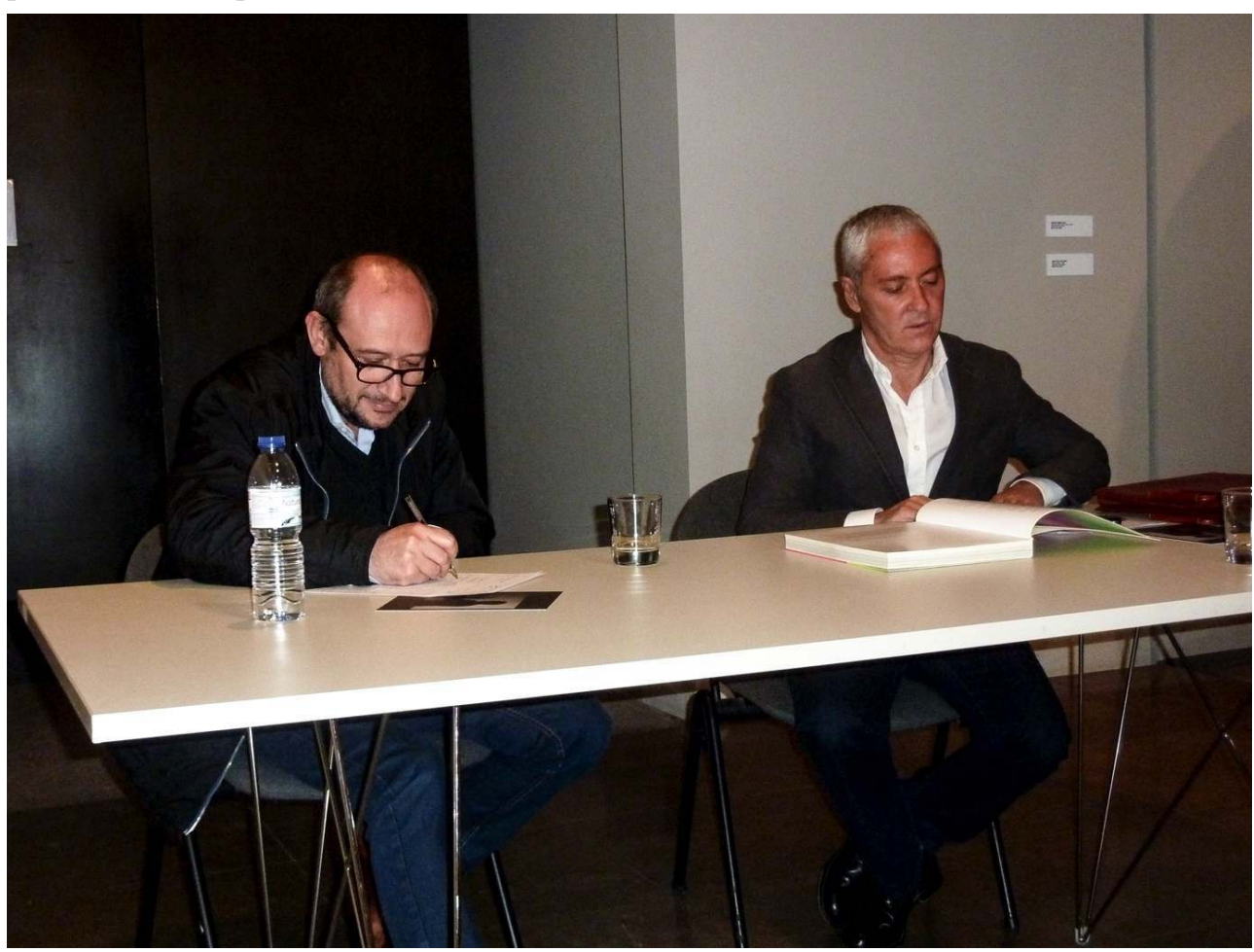

Fig. 1 - Carlos Bessa Pereira e Francisco Capelo, MNAC-MC, 2013

Fotografia de Adelaide Duarte

$\mathrm{O}$ arquiteto lisboeta Alberto Caetano, em diálogo com Rita Romão, Amiga associada, deu a conhecer o modo peculiar como iniciou a coleção, ainda em jovem adolescente (fig. 2). Colecionador apaixonado de gosto eclético, Caetano discorreu sobre a incorporação das obras que foram preenchendo as várias casas que ocupou, num diálogo de cumplicidades estéticas e afetivas. Através do seu testemunho percorreu a história artística portuguesa dos últimos 30 anos, revisitou exposições em museus, em galerias de arte, os leilões e, sobretudo, recordou o relacionamento de grande amizade que construiu com os artistas (Abel Manta, Mário Cesariny, Sarah Affonso, João Vieira, Jorge Molder, Pedro Cabrita Reis, Ana Jotta, Ana Isabel Miranda e Rui Sanches). 


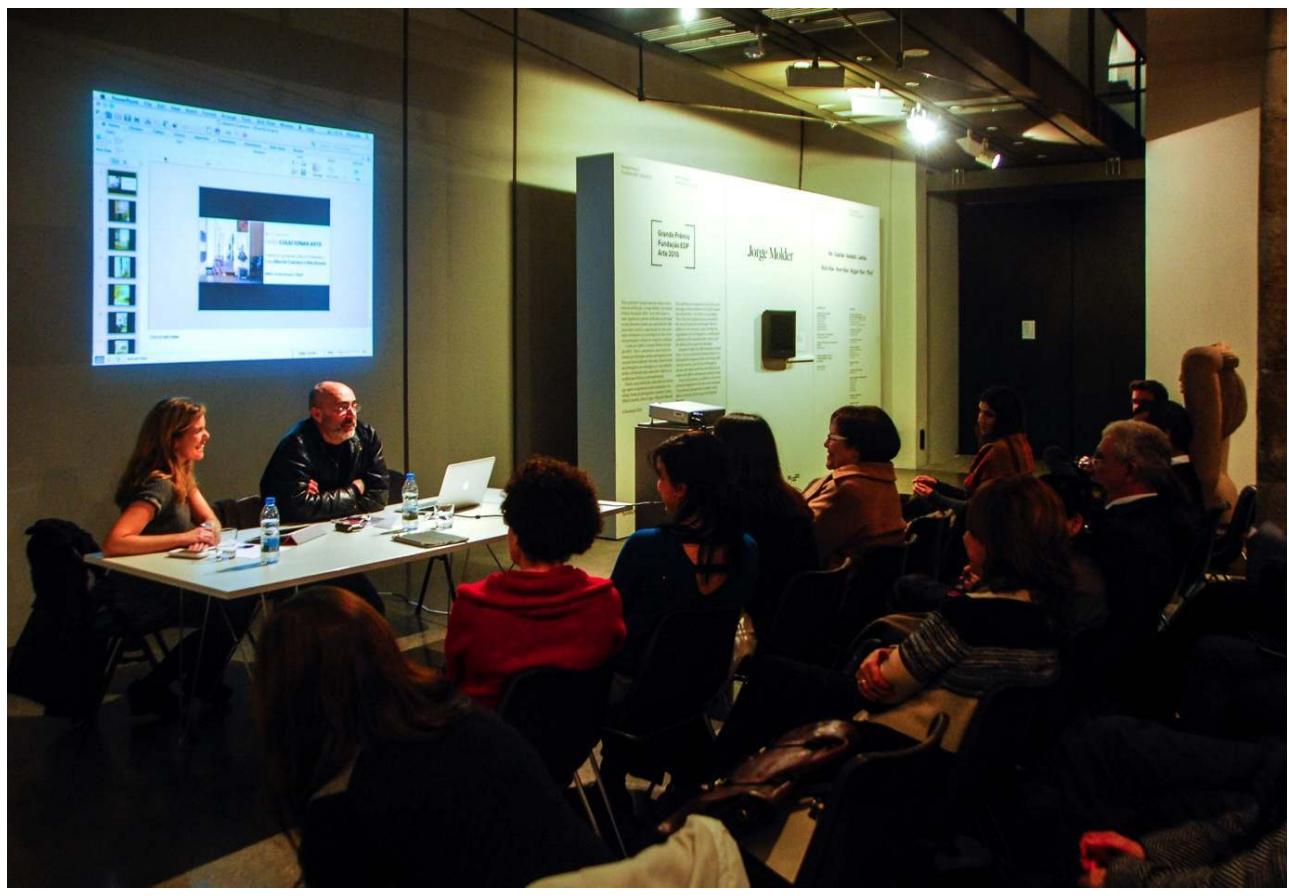

Fig. 2 - Alberto Caetano e Rita Romão, MNAC-MC, 2014

Fotografia de Paulo Garcez

10 Alexandre Melo, crítico de arte e curador, professor com trabalho no domínio da sociologia da arte, revelou uma coleção de caráter intimista (fig. 3). Reunida sem intencionalidade colecionista, a coleção constituiu-se sob a cumplicidade dos artistas, maioritariamente seus amigos (Julião Sarmento, João Vilhena, Albano da Silva Pereira, Douglas Gordon e Lawrence Weiner). Em conversa com David Santos, à época a ocupar a 
direção do MNAC-MC, ficámos a conhecer uma coleção que se configura como o testemunho material de uma vivência no milieu artístico.

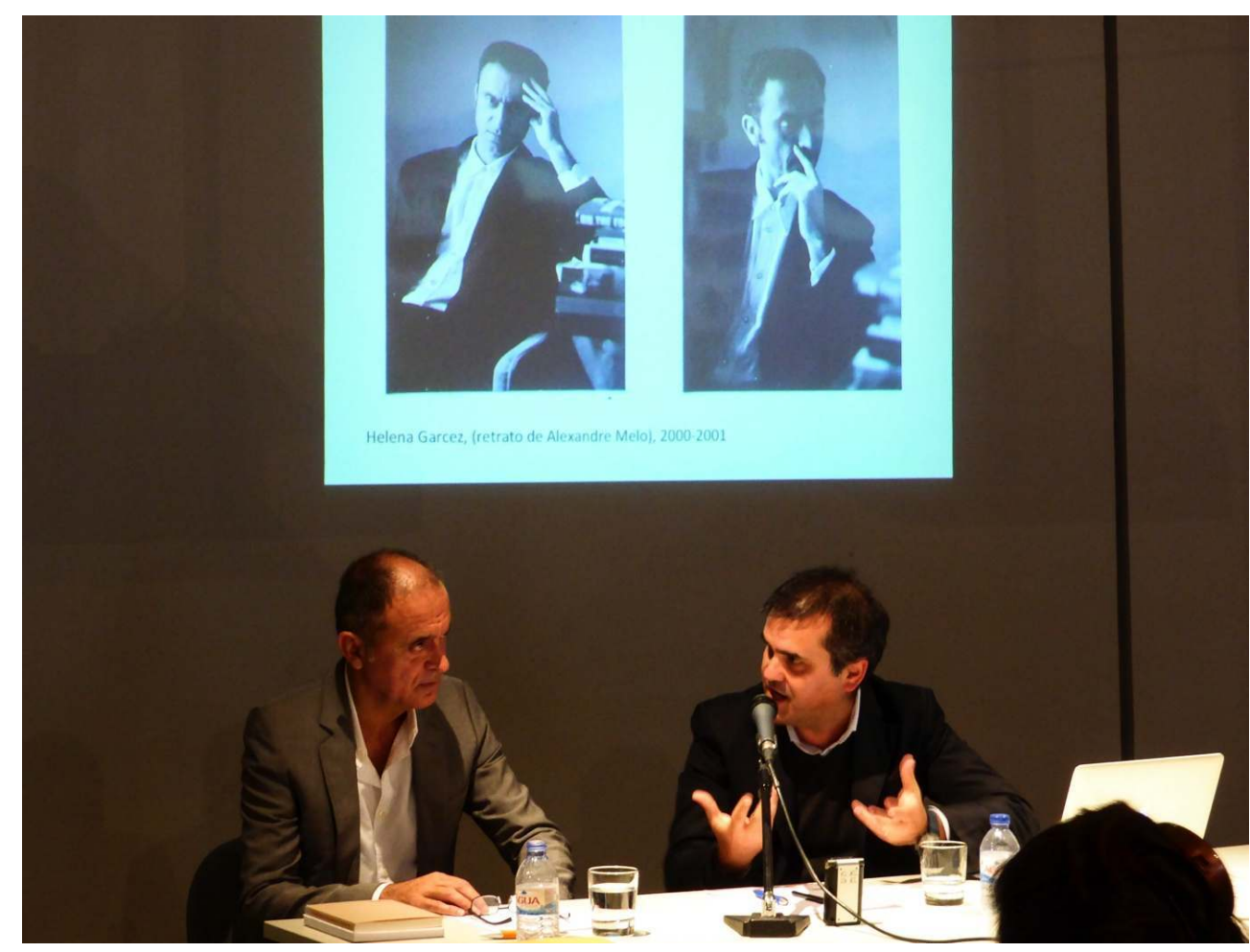

Fig. 3 - Alexandre Melo e David Santos, MNAC-MC, 2014

Fotografia de Ana Rita Bagagem

11 Arlete Alves da Silva, em conversa com Francisco Capelo, discorreu sobre a coleção Manuel de Brito, marido e companheiro de profissão. Fundador da Galeria 111, em 1964, Manuel de Brito é uma figura cimeira na construção do mercado da arte em Portugal ao longo da segunda metade do século XX. A coleção que reuniu espelha, em grande medida, o trabalho que desenvolveu na Galeria, juntando fortes núcleos de alguns dos seus artistas eletivos (Menez, Júlio Pomar, Graça Morais, Paula Rego, António Palolo, Eduardo Batarda, Eduardo Luiz, Bartolomeu Cid dos Santos e António Dacosta). Para além dos artistas que promoveu, Brito adquiriu obras de autores modernistas, algumas de grande qualidade estética (António Soares, Milly Possoz, Mário Eloy, Amor, 1935, Júlio Pomar, Gadanheiro, 1945, hoje no MNAC-MC, e Carlos Botelho). Constituída ao longo de 40 anos, a coleção manifesta uma forte componente histórica pela qualidade das obras e dos autores e configura-se como uma das mais importantes coleções de arte moderna e contemporânea portuguesas no domínio privado. Desde 2006 que a coleção está exposta ao público (Centro de Arte, Coleção Manuel de Brito, Oeiras), assegurada por um protocolo acordado entre o município e os herdeiros de Manuel de Brito, válido até 2017.

José Lima é um empresário bem sucedido da área do calçado, de São João da Madeira, que adquire arte contemporânea desde os anos 1980 (fig. 4). Em diálogo com Raquel Henriques da Silva, testemunhou as vicissitudes da formação da coleção, o alargamento do seu âmbito, o gosto por negociar, as flutuações do mercado da arte, as preocupações sobre o futuro da coleção e o protocolo assinado com o município de São João da Madeira. A coleção representa a arte portuguesa, com destaque para um importante núcleo de obras dos anos 1960 e 1970: Manuel Batista, Lourdes Castro, René Bértholo, Ângelo de Sousa, Álvaro Lapa, Jorge Martins, António Palolo e Joaquim Rodrigo. Mas a sua peculiaridade 
reside na incorporação de um grande número de obras de artistas estrangeiros (Vanessa Beecroft, Sandro Chia, Damien Hirst, Nicholas Hlobo, Anish Kapoor, Kcho, Vic Muniz, Lygia Pape, Michelangelo Pistoletto, Arman, Cindy Sherman e Karel Appel), fazendo dela uma coleção internacional, característica pouco comum no colecionismo em Portugal. Sem curadoria, seguindo o gosto progressivamente afinado pelas conversas com galeristas e, sobretudo, com os artistas (e não descurando a visita a museus), José Lima assume a intuição e a curiosidade como ferramenta aquisitiva privilegiada.

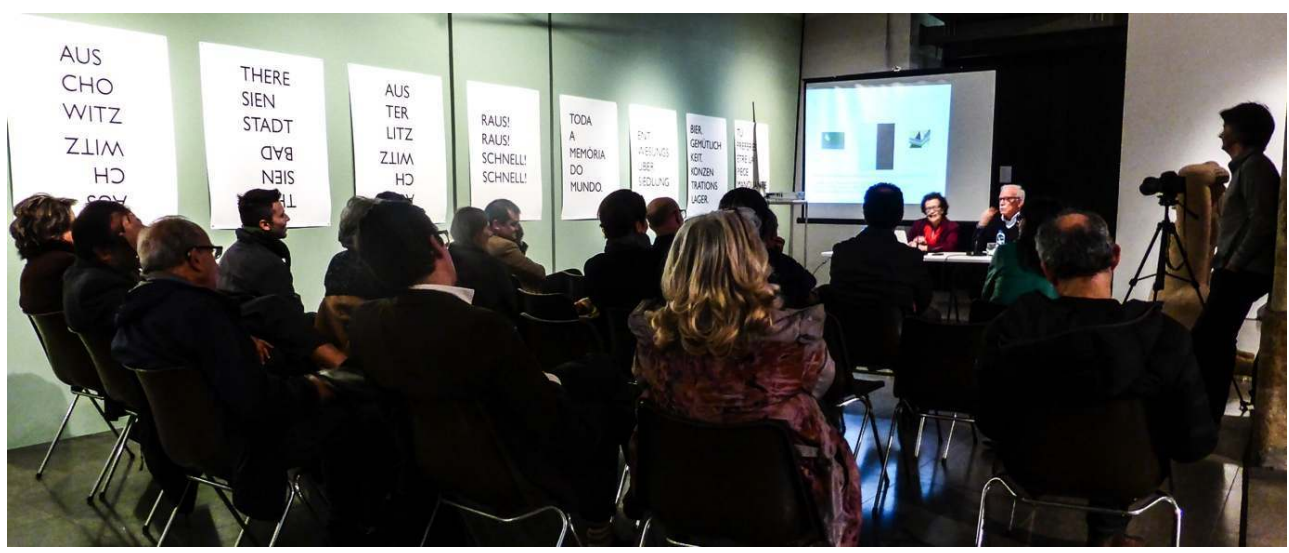

Fig. 4 - José Lima e Raquel Henriques da Silva, MNAC-MC, 2014

Fotografia de Ana Rita Bagagem

Luiz Teixeira de Freitas, advogado brasileiro radicado em Lisboa, conversou com Paula Brito Medori, antiga diretora da extinta revista $L+$ Arte (fig. 5). Em foco estiveram três coleções de arte contemporânea internacionais que desde 2001 tem reunido. Também debateram o contexto artístico da atualidade e a sua preocupação com o papel predominante do mercado no mundo da arte. Colecionador obstinado, começou por definir um tema: a arquitetura, o ambiente, a construção e a desconstrução, vista na perspetiva dos artistas da sua geração e mais jovens, com produção a partir dos anos 1990. Esta foi a sua primeira coleção, muito estruturada. Adriano Pedrosa, comissário brasileiro foi o proponente do tema e o responsável pelas aquisições. A sua colaboração estendeu-se ao desenho, técnica a partir da qual reuniu uma segunda coleção da propriedade da empresa Madeira Corporate Services, da qual Teixeira de Freitas é sócio. Efrain Almeida, Francis Alÿs, Pedro Barateiro, Pedro Cabrita Reis, Maurizio Cattelan, Dinos \& Jake Chapman, Ingar Dragset, Damián Ortega, Lawrence Weiner ou Rui Toscano, são alguns dos artistas da coleção de desenho, hoje depositados no Museu de Arte Contemporânea da Fundação de Serralves. Prescindindo do comissariado, Teixeira de Freitas iniciou um novo projeto que se ajusta à sua grande paixão pela leitura. Trata-se de livros de artistas e documentos ephemera, produzidos a partir dos anos 1960, onde os autores são importantes referências para os artistas que já pertenciam às coleções Teixeira de Freitas. 


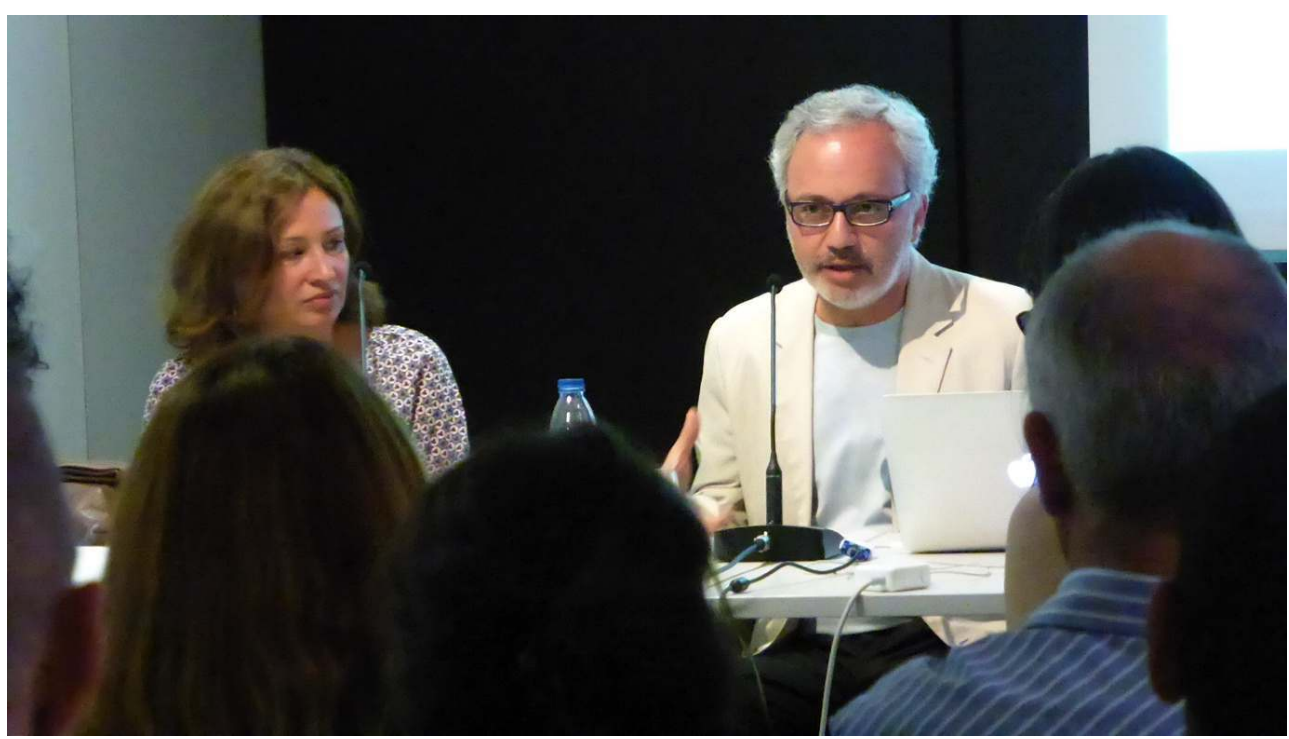

Fig. 5 - Luiz Teixeira de Freitas e Paula Brito Medori, MNAC-MC, 2015

Fotografia de Paulo Garcez

O designer Miguel Rios, em conversa com a curadora Susana Pomba, deu a conhecer o projeto colecionista que desenvolve com o irmão, Manuel Leal Rios. Os dois irmãos iniciaram uma coleção de arte contemporânea portuguesa em 2000, fruto de um diálogo

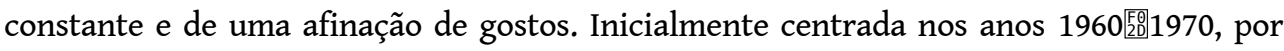
volta de 2004, abriu o enfoque à arte internacional. Álvaro Lapa, António Sena, Helena Almeida, Julião Sarmento, Rui Sanches e Francisco Tropa passou a conviver com Max Frey, Anthony MacCall, Allan Sekula, Matt Mullican, Lawrence Weiner ou Becky Beasley. O discurso que orienta a coleção centra-se na representação do espaço, dos pontos de fuga, da perspetiva, da arquitetura, da política e dos materiais. Sendo privada, a coleção tornou-se acessível ao público desde 2012. A partir desta data é possível ver obras da coleção apresentadas na fundação criada para o efeito, em espaço próprio adaptado. Projeto ambicioso, a sua singularidade reside no enfoque e no objetivo de internacionalização.

\section{A caminho de resultados}

Com uma periodicidade de três sessões anuais, num total de sete conversas realizadas até ao final de 2015, este projeto irá decorrer durante o mandato da atual direção da Associação e com o apoio da direção do MNAC-MC. O balanço deste projeto é ainda provisório. Das sessões realizadas é, todavia, possível aferir artistas eletivos e núcleos de artistas, gostos ecléticos, a importância da amizade e das cumplicidades construídas, as motivações, desde ocasionais a determinadas, à definição de temas para a coleção, ao enfoque nacional e internacional, ao recurso a curadores, à criação do modelo fundacional para exibir as obras, à partilha da coleção com o público e, bem ainda, atestar a participação de um público entusiasta e interventivo nas conversas.

Desejavelmente, estes diálogos com os colecionadores, que configuram uma amostra das tendências da prática colecionista contemporânea em Portugal, serão publicados. A bibliografia sobre o tema em Portugal é escassa e seria um importante contributo da Associação neste domínio. Importa divulgar o modus faciendi colecionista e contribuir para 
contrariar a ideia do colecionar como um art du secret. É também desígnio da Associação aproximar o colecionador do Museu e estimular a filantropia, uma característica pouco enraizada na nossa sociedade por razões de cultura. Em articulação com este ciclo, foi organizada a exposição Eu e os Outros. Coleção Alberto Caetano (2015), a primeira exibição que a direção da Associação organizou no âmbito da linha de trabalho Coleções no MNAC. Desta iniciativa, resultou a doação de Pintura (1949) de Moniz Pereira para o acervo do Museu, uma escolha que o diretor do MNAC-MC efetuou em diálogo com o colecionador.

O ciclo "Colecionar Arte: Conversas a partir de Coleções Particulares" e outras iniciativas já referidas mostram o empenhamento da Associação Amigos do Museu do Chiado no desenvolvimento de iniciativas com o MNAC-MC, colaboração que se tem revelado exigente e desafiante, mas enriquecedora para ambas as partes.

\section{BIBLIOGRAFIA}

Capelo, Francisco. 1996. "The Latent Idea of The Collection." In Sintra Museum of Modern Art. The Berardo Collection, editado por Robert Violette, 9-19. London: [s.n.].

Duarte, Adelaide. 2012. “Da Coleção ao Museu. O Colecionismo Privado de Arte Moderna e Contemporânea, em Portugal, na Segunda Metade do Século XX: Contributos para a História da Museologia." Tese de doutoramento em Letras, área de História e especialidade em Museologia e Património Cultural, Universidade de Coimbra.

Poli, Francesco. 2002. Il Sistema dell'Arte Contemporanea: Produzione Artistica, Mercato, Musei. 3.̣ ed. Roma: Laterza \& Figli Spa.

Pomian, Krzysztof. 2003. Des Saintes Reliques à l'Art Moderne: Venise-Chicago, XIII ${ }^{e}-X X^{e}$ Siècle. Paris: Gallimard.

Schlosser, Julius von. 2012. Les Cabinets d'Art et de Merveilles de la Renaissance Tardive: Une Contribuition à l'Histoire du Collectionnisme (1. a ed. 1908). Préface et posface par Patricia Falguières. Paris: Éditions Macula.

Thomas, Mona. 1997. Un Art du Secret: Collectionneurs d'Art Contemporain en France. Nîmes: Éditions Jacqueline Chambon.

\section{RESUMOS}

Neste artigo apresenta-se o projeto "Colecionar Arte: Conversas a partir de Coleções Particulares" desenvolvido pela Associação Amigos do Museu do Chiado, que consiste no convite a colecionadores privados para apresentarem as suas coleções de arte. Em diálogo dirigido por figuras do meio artístico e académico, este ciclo de conversas proporciona o conhecimento das motivações, do gosto, das escolhas e das tendências que imperam no colecionismo português atual, bem como das características das coleções e das flutuações do mercado da arte. Este ciclo tem contribuído para fidelizar uma audiência interessada em temas do colecionismo contemporâneo, tem aproximado colecionadores do Museu Nacional de Arte Contemporânea - 
Museu do Chiado e permitido valorizar e divulgar as coleções, muitas vezes, inteiramente desconhecidas do público.

In this article, we present the project "Collecting Art: Conversations about Private Collections" developed by the Associação Amigos do Museu do Chiado (Friends of the Museu do Chiado Association), consisting of an invitation to private collectors to talk about their collections. In a dialogue conducted by figures from the artistic and academic fields, this cycle of conversations provides knowledge on the motivations, taste, choices and trends that prevail in current Portuguese private collecting, as well as on the characteristics of the collections and the art market's fluctuations. This initiative has helped maintain an audience interested in themes concerning contemporary art collecting. It has also drawn collectors closer to the Museu Nacional de Arte Contemporânea - Museu do Chiado, and has made it possible to appreciate and reveal collections which are often entirely unknown to the public.

\section{ÍNDICE}

Palavras-chave: Associação Amigos do Museu do Chiado, Museu Nacional de Arte Contemporânea - Museu do Chiado, coleção particular, colecionador, coleccionismo, arte moderna e contemporânea

Keywords: private collection, collector, collecting, modern and contemporary art

\section{AUTOR}

\section{ADELAIDE DUARTE}

Vice-presidente da Associação Amigos do Museu do Chiado. Investigadora no Instituto de História da Arte da Faculdade de Ciências Sociais e Humanas da Universidade Nova de Lisboa com bolsa de pós-doutoramento da Fundação para a Ciência e a Tecnologia. Membro integrado no grupo de investigação Museum Studies: Art, Museums and Collections. Doutoramento em Museologia e Património Cultural (2012) na Universidade de Coimbra; mestrado em Museologia e Património Cultural (2005) e licenciatura em História, variante História da Arte (1998) na mesma Universidade.

Instituto de História da Arte, Faculdade de Ciências Sociais e Humanidades da Universidade Nova de Lisboa, Av. de Berna, 26-C, 1069-061 Lisboa, Portugal, duarte.adelaide@gmail.com 